\title{
LAS TRABAJADORAS SOCIALES \\ EN LA DÉCADA DE 1930. \\ ASISTIR A LOS POBRES Y SERVIR \\ AL ESTADO $^{1}$
}

\author{
María Dolores Lorenzo \\ Universidad Nacional Autónoma de México
}

\begin{abstract}
Concepción Arellano fue detenida el 28 de octubre de 1930 porque la encontraron pidiendo limosna en Avenida Hidalgo. La policía recluyó a la anciana en la cárcel del Carmen de la ciudad de México. Un mes y medio después de su encierro, la inspectora social de la Beneficencia Pública del Distrito Federal, Elvia Carrillo Puerto, la entrevistó y analizó el caso de esta mujer, enferma, de más de 60 años, desempleada, que había sido abandonada en la calle por sus hijos. La inspectora autorizó el traslado de la indigente al Asilo Público de la Beneficencia, argumentando que Arellano carecía del apoyo familiar necesario para vivir y no tenía condiciones físicas para trabajar. Debido a ciertas discrepancias administrativas con las autoridades de la
\end{abstract}

Fecha de recepción: 21 de noviembre de 2017

Fecha de aceptación: 11 de abril de 2018

${ }^{1}$ Una versión preliminar de este trabajo se presentó en el coloquio "Sectores medios en la Ciudad de México". Agradezco los comentarios de Ezequiel Adamovsky, Mario Barbosa, Diego Pulido, Sebastián Rivera Mir, así como la lectura y observaciones de Pamela Fuentes y de los dictaminadores de Historia Mexicana. 
ciudad de México, la disposición tardó casi un año en ejecutarse. No fue sino hasta el 10 de noviembre de 1931 que la anciana compareció ante el jefe del Departamento de Acción Educativa de la Beneficencia, quien ordenó su liberación en los primeros días de diciembre, bajo la promesa de que no reincidiría en el ejercicio de la mendicidad. ${ }^{2}$

La Beneficencia Pública intervino en el caso de esta mendiga y cuestionó el exceso de castigo aplicado a una falta de medios de subsistencia. El procedimiento de liberación fue moroso, pero de esta acción nos interesa destacar que, desde el gobierno, alguien se preguntó "si era justo que la sociedad tratase así precisamente a aquellos de sus miembros peor dotados en la repartición casual de los bienes y, por lo tanto, a los miserables más dignos de consideración". ${ }^{3}$ Y nos interesa explicar cómo y quiénes actuaron en consecuencia.

En la década de 1930, los gobiernos de la posrevolución redoblaron esfuerzos para ampliar el servicio público de asistencia social, y procuraron resolver los efectos nocivos del acelerado crecimiento demográfico y la rápida urbanización de la ciudad. Con el propósito de modernizar el tratamiento de la pobreza urbana, la Beneficencia Pública impulsó la profesionalización de los empleados encargados de inspeccionar, clasificar y asistir a los merecedores del auxilio público. En cuanto a la gestión de estos servicios, el afán modernizador del gobierno promovió la administración centralizada de la Beneficencia del Distrito Federal, y en 1937, se creó la Secretaría de la Asistencia Pública, bajo la dependencia del Gobierno Federal, la cual incorporó ciertos servicios de la asistencia local, como el que realizaban las trabajadoras sociales, en la estructura de la burocracia federal.

A lo largo del texto sostenemos que, a pesar de los indicios de una renovación en los métodos de intervención social que

\footnotetext{
2 AHSSA, BP, As, $A y A$, leg. 6, exp. 1, 11 pp., 1930-1931.

${ }^{3}$ Hugo, Los miserables, cap. V.
} 
blasonó la modernización de este servicio público en México, en esta etapa prevaleció la idea de que el trabajo social era una carrera que merecía sueldos complementarios y se ubicaba en el terreno del empleo ocasional. ${ }^{4}$ Destacamos, en esta historia, la paradoja del Estado posrevolucionario que, por un lado, promovió la expansión de los servicios asistenciales y procuró la especialización de sus empleados y, por el otro, no favoreció la posición de los empleados públicos, particularmente de las trabajadoras sociales encargadas, al ras del suelo, de brindar este servicio público. ${ }^{5}$

Respecto de la incongruencia señalada, más que adentrarnos en la discusión de las formas imperfectas del Estado, estudiarla contribuye a perfilar la doble imagen del Estado en México que, con recursos presupuestales escuetos, forjó un rostro fuerte y autoritario al ampliar y centralizar la asistencia pública, pero que fue débil para empoderar a los empleados públicos que debían ejecutar el servicio de asistencia y poco eficaz en la acción social que destinaron a los pobres. ${ }^{6}$

La historia del trabajo social y su incorporación en la burocracia contribuyen a reconocer la polifónica fuente de actividades técnicas, humanitarias, científicas e ideológicas, que caracterizó la trayectoria germinal de esta profesión en los años

${ }^{4}$ La contradicción entre la oportunidad del empleo para las mujeres y las duras condiciones laborales exigidas en el proceso de profesionalización se muestra como una construcción cultural e histórica en el México de la posrevolución: CANO, "Género y construcción”, pp. 215, 243. Respecto de esta condición para otras mujeres profesionales véase Porter, "Empleadas", pp. 41-63; Guadarrama, "Presencia de la mujer”, p. 125.

${ }^{5}$ Recuperamos la propuesta de los estudios sociales del Estado desarrollada sobre todo en Argentina: Bohoslavsky y Soprano, “Una evaluación”; PloTKIN y ZiMMERMANN, Las prácticas.

${ }^{6}$ Migdal, Estados, pp. 72-73. Migdal retoma los estudios de Nora Hamilton para ejemplificar los contratiempos que suscitó la implementación de políticas públicas de carácter redistributivo en el campo mexicano durante el cardenismo. Respecto de la construcción social del Estado, véase BoHOsLAvsky y SOPRANo, “Una evaluación”, p. 25. 
treinta en México. Los objetivos múltiples para la atención de la higiene, la salud, la educación y la pobreza, así como el carácter mudable de las actividades relacionadas con el trabajo social, han sido constitutivos de esta carrera, que además ha sido ejercida mayoritariamente por mujeres. ${ }^{7}$ En este artículo, particularmente, tenemos interés en mostrar cómo las trabajadoras sociales buscaron un lugar que solventara la utilidad de su empleo para las nuevas funciones del gobierno. Para ello se exploran los elementos que contribuyeron al posicionamiento de las trabajadoras sociales: frente a otras prácticas profesionales, desde la condición inherente de ser mujer y sus respectivas contradicciones, y según las convicciones políticas y sociales del contexto secular y reformista de la posrevolución en México. De esta manera, mostramos la puesta en marcha de una renovada intervención estatal frente a la indigencia, y la respectiva incorporación de estos servicios en la estructura asistencial del gobierno federal, que consiguió la centralización administrativa, pese al ajustado presupuesto público. ${ }^{8}$

\section{UNA PROFESIÓN EN CIERNES}

En la década de 1930 no hubo un modo uniforme para referirse al trabajo social. Ésta era una carrera nueva entre las profesiones dedicadas al servicio de la sociedad. En este sentido, corresponde aclarar que por "trabajadoras sociales”, en este artículo, nos referimos a quienes realizaron labores de clasificación, registro y análisis de los destinatarios de los recursos de la asistencia y que firmaron sus informes como "inspectoras

\footnotetext{
7 Aвrams, "Between Woman", p. 442. Coincidimos con la autora en que la clave para entender el origen de esta profesión está en reconocer el conocimiento interdisciplinario y los múltiples intereses académicos que convergen en el ejercicio del trabajo social.

${ }^{8}$ Respecto de la propuesta de repensar históricamente el campo del trabajo social en México: Ornelas Bernal, et al., "Historia del trabajo", pp. 247-248.
} 
sociales". ${ }^{9}$ Reconocemos también que otras personas, cuya labor fue dirigir proyectos de asistencia social en talleres y centros de atención pública, fueron denominadas "trabajadoras sociales" en la prensa. ${ }^{10}$

De manera fragmentada, las labores auxiliares en educación, justicia, protección a los enfermos y asistencia a los pobres se identificaron como parte del trabajo social. Así, con muchos nombres se reconocieron las actividades que le dieron cuerpo a esta profesión en sus inicios. En el contexto del diseño de la campaña contra la mendicidad de la Beneficencia Pública, en 1930, los "investigadores sociales" se diferenciaron de los "inspectores sociales", en que los primeros centraron sus labores en el análisis sociológico o psicométrico de ciertos grupos de la población mientras los "inspectores sociales", por su parte, entrevistaron y clasificaron a los indigentes. ${ }^{11}$ La diferenciación de estas actividades no derivó en un término que integrara la investigación y la inspección social; de forma escindida, en 1939, la oficina de "trabajo social" asignó salarios para los "investigadores sociales" tipo A, B o C, y consideró algunos cargos para los "inspectores sociales" en su presupuesto. ${ }^{12}$ Con base en lo anterior, argüimos que los quehaceres de inspección fueron esenciales para ubicar la práctica del trabajo social, pero no fueron excluyentes de lo que un investigador social hacía, también, en el campo del trabajo social.

Entre las múltiples actividades de las trabajadoras sociales de la Beneficencia Pública, en su carácter de "inspectoras sociales", ellas clasificaron a los mendigos y utilizaron criterios selectivos

\footnotetext{
9 AHSSA, $B P$, $A s, A y A$, leg. 6, exp. 13, pp. 10, 1930-1931.

10 "Pueden visitar a los mendigos sus familiares y aún sacarlos libres", Excelsior (11 oct. 1930) p. 1. La prensa se refirió a los empleados que clasificaron a los mendigos como "Los empleados especiales de la Beneficencia Pública, inspectores y trabajadores sociales".

11 BeteTA, La mendicidad.

12 Secretaría de Hacienda, Presupuesto, 1939, pp. 560-561.
} 
sobre los pobres que ingresaron en los asilos, escuelas y hospitales públicos de la ciudad de México. Asimismo, estas empleadas repartieron alimentos y cobertores para los indigentes que acudían a los puestos de distribución instalados por el gobierno de la ciudad de México durante la temporada invernal. En cuanto a las tareas de gestión, ellas administraron los talleres para las costureras pobres que inauguró la Beneficencia Pública y, entre otras actividades, impartieron algunas pláticas sobre higiene, además de visitar a los enfermos en los centros de atención social, instalados por la Beneficencia en los hospitales de la ciudad de México.

En el servicio de clasificación de mendigos de la Beneficencia ingresaron mujeres que contaban con instrucción previa de enfermería o en el magisterio. ${ }^{13}$ Por ejemplo, la profesora Rosaura Quiroz de Martínez Garza fue "inspectora" de la Beneficencia en el proyecto contra la mendicidad" ${ }^{14}$ Asimismo, la profesora María Dolores Calderón de Melgar, tras laborar en la clasificación de los mendigos en 1930, tuvo un papel destacado alfabetizando a los trabajadores de la fábrica de cal Productos Americanos. ${ }^{15}$ Como inspectoras, también reconocemos mujeres que carecían del aval de una profesión; Gloria Avilés viuda de Serrano, reina de las fiestas de caridad en Guadalajara, trabajó activamente en un proyecto social conocido como Casa del Pobre; al enviudar, Avilés asistió a los cursos de formación en los métodos de intervención social que impartió la Beneficencia y participó en la clasificación de los mendigos entre 1930 y $1934 .{ }^{16}$

${ }_{13}$ Tal fue el caso de Elisa P. viuda de Guijarro, que trabajó como enfermera de las escuelas de la Secretaría de Educación Pública en 1925. Boletín de la Secretaria de Educación Pública (1ํ mar. 1925).

${ }^{14}$ Colaboradora en el boletín de la asistencia pública en 1934, Asistencia, 1 (ago. 1934), p. 70, directora de la Casa Hogar de la Beneficencia Pública del Distrito Federal, Corpus Christi 8 (ago. 1934), p. 84.

15 "Empresa alfabetiza a sus trabajadores", El Nacional (26 ene. 1946).

16 CASTro, $A$ la sombra de un caudillo, p. 90; "La sociedad mexicana", $E l$ Informador (17 jul. 1919), p. 7; El Informador (10 ene. 1922), pp. 1, 7; "La 
La variedad de nombres utilizados para referirse a las tareas vinculadas con el trabajo social, así como las múltiples formaciones que derivaron en actividades de servicio social, fueron características de esta disciplina en formación. Esto no fue un rasgo particular de las trabajadoras de la Beneficencia Pública, pues en los programas sociales de la Secretaría de Educación Pública, las "profesoras de economía doméstica" y algunas sociólogas tituladas llevaron a cabo tareas de inspección y asistencia social entre sus educandos indigentes. ${ }^{17}$ Las empleadas del Tribunal para Menores Infractores, nombradas "delegadas sociales", formaron parte del cuerpo de expertos en "estudios sociales" que, según el Reglamento para la Clasificación de Menores Infractores de 1926, debían observar el comportamiento de los niños. ${ }^{18}$ Respecto del ámbito de la salud, en la Escuela de Salubridad, entre 1925 y 1929, muchas mujeres obtuvieron el título de "enfermeras visitadoras", con el cual ejercieron actividades relacionadas con la higiene y la salud de una población que consideraron "clientela indigente" ${ }^{19}$ Es así que los empleos vinculados con el servicio social estuvieron lejos de caracterizar actividades rígidas y acotadas a la especialización de un campo disciplinario. ${ }^{20}$

Profesoras, enfermeras, sociólogas y otras personas sin profesión, pero capacitadas en los métodos de intervención social,

sociedad tapatía”, El Informador (17 jul. 1922), pp. 1, 5; también participó en calidad de reina de la corrida de toros a beneficio de hospital de San Camilo: $E l$ Informador (23 dic. 1919), p. 7. Su esposo, Francisco Serrano, ofreció la suma de 2000 pesos para fundar la Casa del Pobre, "La indigencia reaccionaria", revista Mensual Mujer (10 mar. 1927).

17 Calderón Mólgora, “Educación rural”, p. 159.

18 "Reglamento para la calificación de los infractores menores de edad en el Distrito Federal, Distrito Oficial de la Federación”, Gobierno del Distrito Federal (8 de oct. 1926).

19 Agostoni, “Las mensajeras", p. 105.

20 Respecto de la reciente discusión de la formación de profesiones relacionadas con la salud y la higiene: BIERNAT, Historia de la salud y enfermedad. 
realizaron actividades en el campo de la docencia, la orientación, la investigación social y la formación de grupos de la población, así como en la intervención directa frente a los diversos destinatarios que padecían los efectos de la pobreza en la ciudad. De este variopinto escenario de quehaceres y profesiones surgió la especialización del trabajo social, que no se concretó de la noche a la mañana; y diversos factores, además de la etiqueta nominativa y la procedencia educativa, contribuyeron a cristalizar la carrera de las trabajadoras sociales como una profesión autónoma de otros campos, por ejemplo, la enfermería o el magisterio.

\section{LA FORMACIÓN TÉCNICA, UN AVAL}

El trabajo social en la Beneficencia Pública se ejerció sin el reconocimiento formal de un título de trabajadora social emitido por una escuela. Cuando menos, esto no cambió sino hasta $1935 .{ }^{21}$ Por ello, para suplir la carencia de personal especializado, la Beneficencia Pública del Distrito Federal instruyó a sus primeros "inspectores" en el marco de un programa de asistencia social cuyo propósito fue estudiar la pobreza urbana. Entre abril y junio de 1930, Moisés Sáenz, director de la Beneficencia Pública, invitó a Eyler Newton Simpson, sociólogo de la Universidad de Chicago, para que dictara un curso a los "inspectores sociales” de la Beneficencia Pública. Es así que la política pública fue el marco formativo de estos empleados. ${ }^{22}$

La Escuela de Enseñanza Doméstica de la Secretaría de Educación Pública, fundada por Julia Nava de Ruiz Sánchez, fue la primera institución educativa en reconocer el trabajo social

${ }^{21}$ El surgimiento del trabajo social en América Latina y su proceso de profesionalización fueron tardíos en general en la región respecto de otros contextos europeos o de Estados Unidos. Fernández García y Lorenzo García Trabajo social.

${ }^{22}$ Lorenzo, “El análisis de la pobreza”, pp. 1681, 1685-1686. 
como parte de una formación escolarizada en México. ${ }^{23} \mathrm{El}$ objetivo de esta institución residió en formar a las mujeres para la "alta misión” del hogar. El ingreso en la escuela estaba restringido para mujeres mayores de 12 años que hubieran cursado la instrucción primaria. Desde su fundación, la escuela ofreció cursos para “ama de casa”, “corte y confección” y “puericultura”. Además, poco a poco, incorporó otros cursos “libres” relacionados con las labores domésticas, que "pudieran ofrecer un recurso de vida” a las mujeres. En esta sección de cursos libres, germinó la enseñanza escolarizada del trabajo social en México, con la apertura de materias relacionadas con la procuración de la higiene, la alimentación, la salud y la educación. ${ }^{24}$

Cabe señalar que la formación escolarizada se fue convirtiendo en un referente para ingresar en la burocracia asistencial. Así, las estudiantes de la Escuela de Enseñanza Doméstica realizaron sus prácticas de servicio social en los programas de la Beneficencia Pública del Distrito Federal. ${ }^{25}$

En la lógica de incentivar el empleo para las trabajadoras sociales que contaban con cierta formación, el presidente de la República, Lázaro Cárdenas, emitió un acuerdo que recomendó a las dependencias de la Beneficencia Pública que "aprovecharan los servicios de las trabajadoras sociales que se titulan en la escuela respectiva de la Secretaría de Educación Pública”. ${ }^{26}$ Lejos de regular el ejercicio de la profesión, como sucedía en

23 Sanders, Gender and Welfare, p. 127; Evangelista, Historia del trabajo, pp. 74, 92; Castro Sánchez, "Ser trabajadora", p. 10; Ornelas Bernal, et al., "Historia del trabajo", p. 250.

${ }^{24}$ Publicaciones de la Secretaría, "Folleto”, pp. 12 y 21.

25 AHHS, $B P, D, A S$, leg. 14, exp. 19, f. 14. "Versión taquigráfica de la asamblea ordinaria celebrada por la H. Junta Directiva de la Beneficencia Pública, el día 18 de febrero de 1935".

26 "El Presidente de la República, Lázaro Cárdenas. Rúbrica (circular oficial emitida el 12 de agosto de 1936)". México, D.F. a 12 de agosto de 1936. http:// eprints.uanl.mx/8719/1/art4/20/289/29.pdf. Esta escuela es considerada pionera en los estudios formales de trabajo social en México por Valero Chávez, 
otros contextos de la época, ${ }^{27}$ la recomendación de Cárdenas impulsó el empleo de personal capacitado y avalado por un diploma expedido por una escuela reconocida por la Secretaría de Educación Pública.

Si bien la escolarización del trabajo social fue significativa en este periodo de la profesionalización, el despegue formativo del trabajo social en México no se puede disociar de la labor de las voluntarias de la asistencia privada y religiosa en las organizaciones privadas de asistencia. Ellas recibieron cierta formación y sobre todo aquilataron una experiencia práctica en el trabajo social, la cual aplicaron en la organización y atención de diversos centros asistenciales y hospitalarios, como la Cruz Blanca, por mencionar un ejemplo. Sabemos que las voluntarias de las conferencias de San Vicente de Paul y otras mujeres que colaboraban en los servicios sociales que brindaban las parroquias del Distrito Federal, contaron con entrenamiento previo para entrevistar a los pobres en los hospitales y en las prisiones o bien colaboraron en proyectos de alfabetización y de formación en algunos oficios manuales. ${ }^{28}$ Asimismo, los misioneros metodistas y presbiterianos se dedicaron, de manera prioritaria, a la educación en escuelas populares, orfanatos y asilos para indigentes, e incidieron en el amplio espectro del auxilio social en México. ${ }^{29}$

El trabajo social; SANDERs, Gender and Welfare, p. 124; EvANGELISTA, Historia del trabajo; CASTRo SÁnchez, "Ser trabajadora".

27 En Estados Unidos, el trabajo social fue reconocido como una profesión universitaria desde finales del siglo xIx; esta institucionalización posibilitó, por ejemplo, que en el estado de Illinois se restringiera el ejercicio de esta profesión a aquellas personas que contaban con diploma emitido por una institución educativa. KATz, In the shadow, pp. 169-170. Véase "A Bill for an Act in Relation to the Regulation of the Practice of Social Work", en Social Service Review, 7: 4 (dic. 1933), pp. 683-685.

28 Arrom, Volunteering, p. 182. Otro tipo de acciones sociales a nivel parroquial en la Ciudad de México, Crespo Reyes, "Entre la filantropía y la acción”. 29 Bastian, “Modelos de mujer”, p. 165. 
No obstante, el gobierno favoreció la integración de las egresadas de las instituciones y programas que avalaban cierta escolarización; en consecuencia, la circulación de voluntarias de la asistencia privada fue limitada y la escuela fue un medio para secularizar la formación de las trabajadoras sociales.

El comienzo de la profesionalización del trabajo social, por ejemplo, en Chile, donde se funda la primera escuela de trabajo social de América Latina en 1925, promovida por el Ministerio de Asistencia, se dio en un contexto de secularización que procuró profesionalizar el servicio social de las trabajadoras del Estado. ${ }^{30}$

Los años treinta trazaron las pautas para el reconocimiento del trabajo social como una labor técnica y auxiliar de diversos campos del servicio social. En México, la formación impartida en la Escuela de Enseñanza Doméstica, la capacitación brindada a los inspectores en los programas de la Beneficencia, las referencias del quehacer práctico de las voluntarias y el empeño constante de profesionalizar el servicio asistencial, fueron articulando espacios y modelos de formación de trabajo social. Frente al rezago educativo de México respecto de Europa y Estados Unidos, que desde finales del siglo xIx habían incorporado el trabajo social como carrera en las universidades, la Universidad Nacional Autónoma de México (UNAM) inauguró el primer programa de trabajo social universitario, auspiciado por la Facultad de Derecho, en la década de 1940; ${ }^{31}$ consideramos que este reconocimiento otorgó al trabajo social la institucionalización que, en 1930, fue avalada sobre todo por el auspicio de los programas sociales ideados por el Estado posrevolucionario.

30 Illanes, Cuerpo y sangre, pp. 297-303.

31 Biblioteca Nacional, Centro de Estudios sobre la Universidad, fondo Escuela Nacional de Jurisprudencia, Secretaría, Libro de registro de inscripción, c. 22, exp. 33, ff. 144-215, enero 29-agosto 24 de 1942. De los cursos sobre delincuencia infantil surgió la iniciativa de formar la Escuela de Trabajo Social en la UNAM. 


\section{LA FEMINIZACIÓN DEL TRABAJO SOCIAL}

El trabajo social lo ejercieron mayoritariamente mujeres; éste se constituyó como un territorio del quehacer femenino, no sólo en las aulas que formaron a las primeras profesionales, sino también dentro de la estructura administrativa del Estado. En los estudios sobre la burocracia en México, Susie Porter y Mario Barbosa destacan la proporción minoritaria de mujeres contratadas en la administración pública durante el periodo de 1900 a 1940; asimismo, anotan que, durante esos años, hubo un incremento significativo de mujeres empleadas por el Estado. Para el caso del Distrito Federal, Barbosa registró que, en 1900, esta instancia de gobierno empleó a 121 mujeres, y para 1930 este número creció notablemente, pues se registraron 5967 mujeres empleadas por el Distrito Federal. ${ }^{32}$ Por su parte, Porter mostró que el número de empleadas del Estado no sólo aumentó proporcionalmente respecto de los trabajadores del Estado, sino que el tipo de empleos que realizaban las mujeres se diversificó. Según los porcentajes que aporta la autora, las profesoras de la Secretaría de Educación Pública dejaron de ser una mayoría significativa entre las empleadas públicas y, en 1938, la Secretaría de la Asistencia Pública empleó el 57\% del total de las mujeres al servicio del Estado. ${ }^{33}$ Cabe señalar que en la Asistencia Pública las maestras y las enfermeras ocuparon la mayor parte de los cargos.

En coincidencia con los datos de Porter, advertimos que en la estructura administrativa de la Beneficencia Pública las trabajadoras sociales no fueron un grupo mayoritario. ${ }^{34} \mathrm{Y}$

\footnotetext{
32 Barbosa, "Empleados públicos”, p. 144.

33 Porter, "Empleadas públicas", p. 49.

${ }^{34}$ AHSSA, $B P, A s, A y A$, leg. 6. Con base en el registro de los 15 empleados que inspeccionaron a los mendigos en 1930, corroboramos la marcada tendencia hacia la feminización de este servicio, en el cual, para el caso de las campañas contra la mendicidad, participaron 2 varones y 13 mujeres. Cuantificación
} 
destacamos, además, que la dirección de la Beneficencia no tuvo interés en ampliar el número de empleadas dedicadas al trabajo social, pues ante la propuesta de reactivar las campañas contra la mendicidad y contratar a 300 trabajadoras sociales, la Junta de la Beneficencia rechazó la idea, argumentando que no había personal preparado para ocupar estas plazas..$^{35}$ Tampoco hubo un incremento significativo de los cargos relacionados con el trabajo social cuando se creó la Secretaría de la Asistencia, pues en la nómina de empleados, los inspectores, trabajadores e investigadores sociales inscritos en esta dependencia no superaron las 50 plazas. ${ }^{36}$ Quizá valga señalar que la Beneficencia Pública del Distrito Federal careció de recursos públicos para ampliar su planta, pues se suprimieron diversos ingresos en favor de la federalización, que trataremos de manera más amplia en el último apartado.

Otro aspecto que cabe resaltar de la incorporación de las trabajadoras sociales en el sistema de asistencia pública es que ellas debieron buscar su lugar y reconocimiento en una estructura cuya composición laboral la formaban predominantemente varones dedicados al servicio de salud. En 1926, el total de empleados de la Beneficencia Pública era de 2561 personas; de éstas, 652 empleados eran médicos, internos, externos y practicantes; enfermeros y enfermeros aspirantes. Una cuarta parte del total de los empleados y colaboradores del servicio de la Beneficencia en la nómina de la Beneficencia Pública eran

propia a partir de una muestra de 70 entrevistas realizadas a los mendigos. La carrera de trabajador social, en las décadas posteriores a los años treinta, siguió siendo territorio casi exclusivo de las mujeres, de acuerdo con los datos que proporciona SANDERS, Gender and Welfare, p. 122. Entre 1940 y 1956, 9 varones ingresaron en la Escuela de Trabajo Social.

35 AHSS, $B P, D, A S$, leg. 14, exp. 18, ff. 1-21. "Versión taquigráfica de la asamblea ordinaria celebrada por la H. Junta Directiva de la Beneficencia Pública, el día 11 de febrero de 1935."

36 Secretaría de Hacienda, Presupuestos, 1939, pp. 560-561. 
médicos y enfermeros. ${ }^{37}$ En esta nómina no hubo registros de salarios asignados a trabajadoras o inspectoras sociales, lo cual indica que, en 1930, cuando la Beneficencia inició las campañas contra la mendicidad, las trabajadoras sociales fueron un grupo minoritario de mujeres que irrumpió en un ámbito de servicio social mayoritariamente masculino.

Los dispositivos socioculturales que sustentaron la feminización del trabajo social contribuyeron al posicionamiento de esta profesión que debía desarrollarse en competencia con otras carreras como la de derecho y la de medicina, predominantemente masculinas, o frente al magisterio y la enfermería, profesiones femeninas que habían entrado en la burocracia de manera profusa desde finales del siglo XIX.

Las trabajadoras sociales afirmaron la naturalización de los saberes disciplinarios con base en la condición biológica de ser mujer y su propensión "virtuosa” hacia el altruismo. La idea preconcebida de que "hacer el bien a la humanidad" era inherente al carácter femenino no fue una imposición de los hombres en una guerra de sexos; más bien, como expuso Josefina Ilizarriturri, trabajadora social de la Beneficencia, la labor del servicio social enalteció su posición en relación con un conocimiento específico, y sobre "el gran hombre" que se jactaba de ser el conocedor de "todo en la vida", ellas eran quienes conocían la verdadera "voz del pueblo", porque "habían descendido hasta los barrios bajos, hasta la entraña palpitante de la miseria del pauperismo horripilante" ${ }^{38}$ El espíritu de servicio les concedía, así, cierta identidad disciplinaria y un objetivo de trabajo acotado a su condición de ser mujer.

Paradójicamente, si la feminización del trabajo social resguardaba, para las mujeres, un empleo en la Beneficencia, también,

${ }^{37}$ La Beneficencia Pública en el Distrito Federal (jul. 1927), p. 10. ${ }^{38}$ Josefina Ilizarriturri, "La Voz del Pueblo", Asistencia. Órgano Oficial de la Beneficencia Pública en el Distrito Federal (oct. 1936), p. 39. 
esta supuesta propensión natural al altruismo y al servicio social fue el cauce para que su labor se ejerciera sin remuneración o bien como una actividad merecedora de salarios bajos y complementarios. ${ }^{39}$ Es decir, cuando el Estado abrió para las mujeres la posibilidad de insertarse en ciertos espacios de la administración pública, éstas debieron cubrir un amplio abanico de habilidades y destrezas, propias de su sexo, que legitimaron su posición en la gestión pública; no obstante, estas actividades exigieron "mucho trabajo y mal pagado".

Por "mucho trabajo" me refiero a que ellas cubrían turnos de 29 horas seguidas en labores ininterrumpidas de inspección y clasificación de los pobres; por ejemplo, en la campaña contra la mendicidad, durante el verano de 1933, la sección de investigación, a la que pertenecían las "inspectoras sociales”, comenzó las entrevistas a los mendigos a las ocho de la mañana y terminó a la una de la tarde del día siguiente, según describió Excelsior. ${ }^{40}$

Por "mal pagado" me refiero a que la compensación salarial de las trabajadoras sociales en la escala de sueldos de los empleados públicos del ramo de asistencia se ubicó entre los más bajos. De acuerdo con la propuesta de la Junta de Beneficencia para contratar trabajadoras sociales e impulsar la campaña contra la mendicidad en 1935, el salario sugerido para ellas fue de 5 pesos diarios. ${ }^{41}$ En el caso de que esta propuesta se hubiera aprobado, las trabajadoras sociales habrían percibido un sueldo parecido al que recibió, en la oficina de Trabajo y Previsión Social, un aspirante a taquígrafo ( 4.50 pesos diarios) y habrían ganado,

39 En el caso del magisterio, estas características también definieron la posición jerárquica de las mujeres en la estructura de salarios. Respecto de la proporción mayoritaria de mujeres en el magisterio y los salarios complementarios: GALván Lafarga y López Pérez, Entre imaginarios y utopías. BAzAnt, “Análisis comparativo”, pp. 241-242; OLсотт, Revolutionary Women, p. 76.

40 Excelsior (16 ago. 1933), pp. 1 y 8.

41 "Versión taquigráfica de la asamblea ordinaria celebrada por la H. Junta Directiva de la Beneficencia Pública, el día 11 de febrero de 1935”, AHSS, BP, $D, A S$, leg. 14, exp. 18, ff. 1-21. 
aproximadamente, medio sueldo de lo que percibía un pasante de abogado en esta misma oficina (9 pesos diarios). ${ }^{42}$

Pese al escueto sueldo asignado a las trabajadoras sociales, el pago que ofreció el Estado fue reivindicativo de una labor que, en esos años, lo realizaban las mujeres de manera altruista y voluntaria, sin compensaciones de dinero en efectivo, por ejemplo, en algunas organizaciones de asistencia privada y religiosa. La distinción que supuso la asignación de un salario como empleada pública no fue, sin embargo, una motivación para que las voluntarias de las instituciones de asistencia priva$\mathrm{da}$ ingresaran en las filas de la burocracia, ni hemos registrado una cooptación masiva de voluntarias al servicio de la Beneficencia Pública. ${ }^{43}$ Esto no se explica solamente por la escueta remuneración asignada al trabajo social: valga reiterar que el número de plazas que ofreció la burocracia para las trabajadoras sociales fue reducido y, en consecuencia, no hubo, en general, una amplia oferta laboral en la burocracia del Estado.

\section{EL COMPROMISO SOCIAL}

El discurso de la modernización de la asistencia pública se entreveró con un proceso intenso y radical de secularización, el cual exhibió la necesidad de distinguir las acciones caritativas de aquellas funciones emprendidas por la burocracia asistencial. ${ }^{44} \mathrm{Si}$ bien las corporaciones civiles y eclesiásticas habían sido desplazadas de la administración de la Beneficencia Pública desde finales

\footnotetext{
42 Secretaría de Hacienda, Presupuesto General de Egresos de la Federación para el año fiscal de 1933, México, Talleres Gráficos de la Nación,1933.

43 Respecto del fluido tránsito entre enfermeras que laboraban en obras de asistencia pública y pasaron a la asistencia del Estado para el caso colombiano: Castro Carbajal, La relación, p. 160; en Argentina: Biernat, et al., La salud pública (caps. VIII-X).

${ }^{44}$ Guadarrama y Riguzzi, "La trayectoria”, pp. 42-43. A partir de 1933, el Estado ejerció un inusitado control sobre la Junta de Beneficencia Privada por medio del jefe del Distrito Federal.
} 
del siglo xIx, en los años treinta, el discurso renovado de la secularización se guarneció de esta tradición liberal. ${ }^{45}$ En este contexto, el posicionamiento de las trabajadoras sociales no obvió el compromiso ideológico ni los valores laicos y reformistas de la Revolución, lo cual constituyó un distintivo para las mujeres que asistieron a los pobres desde las instituciones del Estado.

El trabajo social no se practicó meramente como una vocación altruista. Tanto las voluntarias como las trabajadoras sociales de la Beneficencia Pública laboraron por el bienestar de los niños y las mujeres desvalidos; además, dedicaron su trabajo al servicio de grupos de indigentes. Pero a diferencia de las primeras, la ideología socialista, la lucha obrera y los principios asociativos de las segundas buscaron revertir el orden social y económico, otorgando por derecho los recursos que concedía el Estado, lo cual las identificó con los principios revolucionarios que enarboló la Beneficencia Pública como promotora de la justicia social. ${ }^{46}$

La cercanía de las trabajadoras sociales con los obreros, las mujeres necesitadas y los desvalidos las hizo más visibles en un gobierno que aspiró a revertir las condiciones de pobreza en la ciudad. Un caso emblemático de estas mujeres y su compromiso político con el bienestar social de los pobres es el de Elvia Carrillo Puerto, destacada activista política, feminista y socialista. ${ }^{47}$

45 Desde los años sesenta del siglo xix, inició un proceso de centralización administrativa del ramo público de la Beneficencia, pero esta reforma, inacabada, fue interrumpida por el estallido de la Revolución en 1910: algunas instituciones de asistencia y salud quedaron bajo la dependencia del Gobierno federal, mientras que otros establecimientos de auxilio público siguieron siendo responsabilidad del gobierno del Distrito Federal. Lorenzo Río, “Ley y eficacia".

46 Arrom, Volunteering, pp. 183-185. Señala que, en su extenso servicio humanitario, las voluntarias no promovían la transformación hacia una sociedad igualitaria que asistiera, por derecho, las necesidades de los indigentes. Mitchell y SCHELl en The Women's, muestran la acción social de grupos católicos y su efectividad en la acción social.

47 Lemaitre, Elvia Carrillo Puerto; Tuñón Pablos, Mujeres; Sauri Rianсно, "Violencia política", pp. 84-106. Después del asesinato de sus hermanos 
La "monja roja", como también se le conoció, fue una activa colaboradora de las organizaciones políticas de mujeres, que integraron las demandas de los trabajadores en los derroteros de la lucha social. Entre 1930 y 1931, Elvia Carrillo Puerto se incorporó como inspectora de la Beneficencia.

En el tenor de la época, estas mujeres encontraron un camino para la reivindicación de sus derechos, orientando su trabajo hacia las actividades relacionadas con la protección social de los niños indigentes y los obreros. ${ }^{48}$ Como empleadas públicas, estas mujeres se identificaron con las demandas de las organizaciones femeninas, que confrontaron los embates de los hombres que cuestionaron el empleo de la mujer en la burocracia estatal. ${ }^{49}$ Entre 1930 y 1933, algunas inspectoras del servicio de la Beneficencia Pública colaboraron con las organizaciones que se opusieron a las manifestaciones que pedían la eliminación de los cargos que ocupaban las mujeres en actividades comerciales, industriales y burocráticas. ${ }^{50}$ Por mencionar dos ejemplos de trabajadoras sociales involucradas en esta lucha, Belén Gutiérrez de Mendoza encabezó la corriente política República Femenina en el Frente Único Pro Derechos de la Mujer, y Concepción Canfield se convirtió en secretaria de la Liga Femenina de Asistencia Social en 1936.51

llegó a la ciudad de México perseguida por sus ideas en favor de los derechos políticos de la mujer en Yucatán, los cuales defendió durante la gubernatura de su hermano, Felipe Carrillo Puerto y, posteriormente, en su carácter de diputada electa de la XXLIII Legislatura de Yucatán.

${ }^{48}$ Cano, Se llamaba Elena. Esta biografía social es un extenso estudio de género que da cuenta de cómo se concibieron las mujeres, autónomas e independientes, relacionadas con los proyectos de bienestar en las primeras décadas del siglo Xx.

${ }^{49}$ PorTer, "Empleadas públicas”, pp. 46 y 52.

50 Porter, "Empleadas públicas", p. 52. Revisar las manifestaciones de los tranviarios y de los obreros de la Confederación General de Trabajadores estudiada por Porter.

${ }^{51}$ Cano, "Las feministas en campaña”, p. 352. Asistencia. Órgano Oficial de la Beneficencia Pública en el Distrito Federal, 11 (sep. 1936). 
La intensa y combativa experiencia organizativa, sin embargo, fue tangencial de las habilidades y las destrezas que exigió el servicio en la Beneficencia. ${ }^{52}$ Seguramente, el derrotero de la lucha de los derechos sociales le dio coherencia social al heterogéneo grupo de empleadas dedicadas al trabajo social, pero estos compromisos no suplieron la exigencia de la práctica profesional basada en conocimientos técnicos y formación en los métodos de intervención social.

\section{LA INSPECCIÓN EN LA PRÁCTICA}

En el entendido de que el servicio asistencial cumplía con el propósito de analizar "científicamente" los problemas de la ciudad, el trabajo social en la Beneficencia Pública esgrimió su principal aportación para el gobierno de los pobres desde el Estado, aplicando procedimientos y metodologías de la intervención social en los programas de protección a la pobreza urbana. Las autoridades de la Beneficencia Pública reconocían la incipiente formación de las inspectoras, pero también destacaban, positivamente, su colaboración en la recopilación de datos de la vida de los pobres.53

Para cumplir con el protocolo de atender la indigencia con nuevos métodos, las trabajadoras sociales recabaron y verificaron los datos cuantitativos (sexo, edad aparente y condiciones físicas) de los mendigos. Se desplazaron por las colonias más miserables de la capital para recoger testimonios de vecinos y familiares, cotejando la versión de los pobres entrevistados, y con esta información, elaboraron la caracterización de los merecedores de los recursos de la Beneficencia.

${ }^{52}$ La posición radical de algunas maestras en la posrevolución también definió la trayectoria profesional por ejemplo en el caso de la profesora Cuca García en Michoacán. Oıikión, “Cuca García,” p. 58.

53 Beteta, La mendicidad, p. 4. 
Las entrevistas aplicadas a los pobres por las inspectoras aportaron una base técnico-científica sobre la cual se construyó el perfil de los destinatarios de los programas de auxilio público. Estos instrumentos apuntalaron la relación desigual entre las trabajadoras sociales y sus entrevistados: las empleadas de la Beneficencia, investidas por su cargo, mantuvieron una posición por encima de los indigentes que estudiaron, y de sus observaciones dependió el destino asistencial de los pobres recogidos por el gobierno.

La distancia entre el mendigo y la inspectora tampoco concedió poder ilimitado a la empleada de la Beneficencia, que se ajustó a los dispositivos técnicos ideados por las autoridades para focalizar la ayuda hacia destinatarios específicos de una política pública. En este contexto, operó una comunicación intermedia entre las autoridades de la Beneficencia que diseñaron la política social, las trabajadoras sociales y los destinatarios, sobre los cuales se atribuyeron las características de "deseables" o “indeseables".

El primer criterio de distribución de los recursos que los inspectores de la Beneficencia consideraron fue el carácter residual del sistema de asistencia; es decir, las inspectoras concedieron el auxilio del Estado a los indigentes cuando éstos carecieron de redes familiares de ayuda. Por eso, casi la mitad de los pobres liberados en la redada de 1930 fueron entregados a sus familias o a quienes dieron garantías de que se ocuparían de su cuidado. Con base en los criterios dados por las autoridades, las inspectoras tenían el cometido estricto de conceder auxilio sólo a los "desamparados", incapacitados físicos o mentales que carecieran de medios (familia o trabajo) para subsistir. Para otorgar esta ayuda a los "verdaderamente" necesitados, las trabajadoras sociales restringieron el acceso de los servicios a las personas que "simulaban" condiciones de pobreza. ${ }^{54}$

${ }^{54}$ Lorenzo, "El análisis de la pobreza”. 
Como representantes de la Beneficencia, las inspectoras tenían la misión de reconocer a los pobres que mostraban un caudal de carencias, entre ellas, la falta de trabajo, para concederles auxilios del Estado. La Beneficencia no se ocupó de aquellos pobres considerados capacitados para trabajar, en el entendido de que los individuos tenían la obligación de proveerse una forma de subsistencia. Es así que la mitad de la población concentrada en la Beneficencia fue liberada cuando la clasificaron como personas "sin trabajo", desocupados, que demostraron la posibilidad de recuperar el trabajo perdido o asentaron, en la entrevista, la garantía de que lo habían recuperado. ${ }^{55}$

$\mathrm{Al}$ ejecutar los dispositivos clasificatorios sobre los pobres, las trabajadoras sociales cumplieron con las expectativas reformistas de la Beneficencia posrevolucionaria: la incapacidad para laborar y la carencia de redes de apoyo para subsistir como características del destinatario de la asistencia pública. ${ }^{56} \mathrm{Busca-}$ ron superar el papel de inspectoras "morales" que otras mujeres habían llevado a cabo en programas oficiales promovidos, por ejemplo, por las ligas de la temperancia en Michoacán. ${ }^{57} \mathrm{La}$ ficha de inspección que las trabajadoras sociales utilizaron en sus entrevistas pretendió neutralizar la subjetividad de la construcción del relato de los pobres urbanos. Pero la mediación de las trabajadoras no fue ajena de la valoración moral y estigmatización de los pobres. Con todo, el uso de cierta metodología contribuyó a la construcción técnica del beneficiario sobre el cual se focalizaron los recursos de la asistencia social en la

\footnotetext{
${ }^{55}$ Lorenzo, "El análisis de la pobreza".

${ }^{56}$ AHSS, $B P$, $A S$, DAES, leg. 2, exp. 6, ff. 1-9. "Informe que rinde a la H. Junta Directiva de la Beneficencia Pública el Departamento de Acción Educativa, Eficiencia y Catastros Sociales, correspondiente a las labores de los días 6 de febrero a 4 de marzo de 1931" (febrero 1937). Es así que, de los 506 mendigos concentrados en la Beneficencia en 1930, 116 fueron internados en instituciones de asistencia y 274 quedaron libres; aparte, 76 personas fueron recluidas en las cárceles.
}

57 Olсотт, Revolutionary Women, pp. 76-77. 
ciudad de México, perfilando una nueva manera de concebir y tratar la pobreza en la ciudad.

\author{
PROGRAMAS SOCIALES DISCONTINUOS \\ Y ACTIVIDADES DE OCASIÓN
}

Los programas de protección social contribuyeron parcialmente a brindar estabilidad al empleo de las trabajadoras sociales. Los objetivos de la política social en la década de 1930 oscilaron entre la intensidad de la atención asistencial para los desvalidos, el fortalecimiento de la intervención policiaca sobre la pobreza criminalizada y la focalización sobre ciertos grupos de indigentes. ${ }^{58}$ En consecuencia, las trabajadoras sociales se ocuparon de levantar censos y elaborar fichas técnicas cuando la Beneficencia lo consideró pertinente; así, en 1930, levantaron una especie de censo y el reconocimiento individual de los pobres mediante el estudio de caso de los indigentes en las campañas contra la mendicidad.

Sin embargo, con el relevo de la dirección de la Beneficencia en 1933, se desvaneció el énfasis en atender a los mendigos. En cambio, las autoridades impulsaron "las brigadas de invierno". Según argumentó el general Tapia, director de la Beneficencia, con la supresión de las campañas contra la mendicidad evitaban el "lento proceso" de clasificación de los pobres y eludían el "costoso" compromiso del internamiento de los enfermos e indigentes desvalidos en asilos y hospitales, que siempre estaban sobrados de gente. Con cierto desdén hacia el estudio de caso y la clasificación del indigente, expuso que el nuevo propósito de la Beneficencia debía seguir los siguientes lineamientos: "si encontramos a un individuo en estado de ebriedad o a un niño desvalido por la miseria, que no tiene abrigo ni qué comer, nuestra obligación no es ver de qué vicio padece, sino nuestra

58 LORENZo, "La acción asistencial". 
obligación es recogerlo y llevarlo a un lugar donde esté al abrigo del tiempo y donde se le pueda dar un mendrugo de pan y una taza de café". ${ }^{59}$ Así pues, el minucioso proceso del estudio y análisis de caso de los mendigos que elaboraron las trabajadoras sociales entre 1930 y 1932 fue desplazado por la extenuante labor de distribución nocturna de café, atole y cobertores entre los pobres de la ciudad.

La prensa exhibió que, en las brigadas nocturnas, la Beneficencia atendía a más de 4400 personas que concurrían, por la noche, a los puestos de café y atole. Con base en el principio utilitario de atender al mayor número de personas con el menor número de recursos, la brigada era preferible al tratamiento de la mendicidad, pues ampliaba la cobertura asistencial, ya que el número de mendigos atendidos en las campañas apenas rebasaba las 1500 personas asistidas por semestre..$^{60}$

Además de los objetivos mudables de los programas de asistencia que no favorecían la especialización del quehacer cotidiano de las trabajadoras sociales, cabe resaltar que estas empleadas de la Beneficencia carecían de un espacio laboral establecido para llevar a cabo las tareas de inspección o de distribución de recursos. Por el tipo de actividad que realizaban, ellas circulaban en las calles recogiendo mendigos o repartiendo víveres, acudían a las cárceles y a los diferentes establecimientos de asistencia para entrevistar a los menesterosos y recorrían la ciudad para verificar e inspeccionar a los sujetos de sus estudios, entre otras tareas que implicaban movilidad.

${ }^{59}$ AHSS, $B P, D, A S$, leg. 14, exp. 18, ff. 1-21, "Versión taquigráfica de la asamblea ordinaria celebrada por la H. Junta Directiva de la Beneficencia Pública, el día 11 de febrero de 1935".

60 "Activa proporción de la Beneficencia con los pobres", Excelsior (26 nov. 1936), pp. 1, 6. En los recuentos estadísticos elaborados por los inspectores se mencionaba la proporción de hombres y mujeres, adultos y niños, además del número de indigentes trasladados a los dormitorios públicos en las noches frías de invierno. 
En 1936, el director de la Beneficencia Pública presentó una iniciativa que brindó cierta regularidad para las labores de servicio que ejecutaban las trabajadoras sociales, se trató de la instalación de una especie de oficina de representación de los establecimientos de Beneficencia. Al respecto, El Universal anunció la inauguración de diez estaciones de asistencia social para operar como sucursales y atender, de forma rápida y eficaz, a los pobres: una trabajadora social se ocuparía de la jefatura de la estación y, a su cargo tendría dos ayudantes que visitarían periódicamente diversos centros de salud y asistencia, además de impartir pláticas de higiene y prevención social. ${ }^{61}$

Otra moción que perfiló cierta estabilidad para el trabajo social fue la creación de un taller de costura para mujeres menesterosas. El director de la Beneficencia, Enrique Hernández Álvarez, inauguró el taller de costura establecido en el dormitorio público número 2, ubicado en la Plaza de San Salvador el Verde, en 1937. Las trabajadoras sociales Josefina Gaona, María Luisa Beltrán, Eleonora Re, Josefina Ilizarriturri, Emma I. de Chávez y Ana María Martínez, asistieron a la inauguración del taller. ${ }^{62}$

La importancia concedida por el Estado al trabajo social fue confeccionando espacios para cuadros profesionales que guiaban la acción pública y daban sus primeros pasos hacía la institucionalización de un quehacer especializado del servicio público relativo a la protección social.

EL PASO DE LA ASISTENCIA

HACIA LA BUROCRACIA FEDERAL

El ascenso de Lázaro Cárdenas a la presidencia de la República, en diciembre de 1934, trazó un nuevo rumbo administrativo para

61 El Universal (4 jun. 1936), p. 1.

62 Asistencia. Órgano Oficial de la Beneficencia Pública en el Distrito Federal, 15 (ene. 1937), p. 45. 
la Dirección de la Beneficencia Pública. No sólo por el discurso en favor del mejoramiento social y el tipo de servicio que debía brindar el Estado a los pobres, sino por la estructura de gestión pública proyectada para la Beneficencia del Distrito Federal.

El proceso de centralización administrativa recurrió a una fórmula que consistió en reducir, desde la federación, los recursos que ésta aportaba para el sostenimiento de la Beneficencia del Distrito Federal, lo cual explica por qué, durante los dos primeros años del gobierno de Lázaro Cárdenas (1934 y 1936), la Beneficencia Pública resintió la reducción de sus ingresos y, entre otros efectos, operó con recursos muy limitados para expandir la planta de empleados que atendía a una creciente población de destinatarios de este servicio público. ${ }^{63}$

Los miembros de la Junta de la Beneficencia Pública insistieron en que debían incrementar los ingresos de esta dependencia si quería subsistir como instancia de protección social en la ciudad; reconocían los límites impuestos por el Gobierno federal para ampliar sus ingresos, y señalaban que entre 1934 y 1935, la federación había exigido, para sus arcas, la contribución de un millón de pesos que la Beneficencia de Distrito Federal recibía por cuenta de la Lotería Nacional. Con ello, impulsarían la cobertura asistencial en los estados. Otro recorte sustantivo en los ingresos de la Beneficencia Pública fue que ésta dejó de percibir 400000 pesos que subvencionaba el Departamento Central. ${ }^{64}$ Y para colmo de la Beneficencia Pública, el impuesto por sucesiones y donaciones disminuyó a causa de la incertidumbre que provocó el control inusitado que el Gobierno federal impuso sobre las instituciones de la

${ }^{63}$ El Universal (7 nov. 1935), p. 5; AHSS, BP, D, AS, leg. 19, exp. 7, ff. 2-9, "Versión taquigráfica de la asamblea ordinaria celebrada por la H. Junta Directiva de la Beneficencia Pública, el día 4 de mayo de 1936".

${ }^{64}$ AHSS, $B P, D, A S$, leg. 15, exp, 27, ff. 1-14, "Versión taquigráfica de la asamblea ordinaria celebrada por la H. Junta Directiva de la Beneficencia Pública, el día 29 de abril de 1935" (29 abr. 1935). 
Beneficencia Privada, con la promulgación de la Ley de Beneficencia Privada de $1934 .{ }^{65}$

El panorama crítico de las finanzas de la Beneficencia Pública ayudó a concretar la federalización de esta instancia de gobierno local.66 Así, que la federación suscitara el aprieto económico de la Beneficencia Pública del Distrito Federal fue una estrategia de gestión efectiva que condujo a la centralización administrativa de este servicio público en la ciudad.

El médico Enrique Hernández Álvarez, como director de la Beneficencia, aquilató la idea de que el gobierno debía brindar asistencia social integral, en contraposición al "viejo concepto" de la caridad, e incluso a la idea de beneficencia entendida como una dádiva. Según Hernández, la Beneficencia Pública no había podido desprenderse "de la rutina ideológica y de servicios que les legara aquella organización social burguesa que les dio vida y que la Revolución viene tratando de substituir". ${ }^{67}$ Para conseguirlo era necesario acudir al Gobierno federal.

Pese al encono que suscitó entre la Junta Directiva de la Beneficencia Pública del Distrito Federal la supresión de algunas funciones asistenciales, en enero de 1936, Hernández anunció que la intervención de la Federación era inminente. Con esta reforma, podría cubrirse la insuficiencia del servicio asistencial en la ciudad de México, además de saldar las deudas de la Beneficencia y expandir los servicios sociales hacia otros estados de la República. Para atenuar la incertidumbre de los empleados de la Beneficencia, Hernández anunció que, para ejecutar la reforma, el gobierno requería de maestros rurales, enfermeros, parteras, cocineras y "trabajadoras sociales". Todos ellos, según Hernández, habían

65 Guadarrama y Riguzzi, “La trayectoria”, p. 44.

66 Respecto a la creación de la Secretaría de Asistencia Pública, Aréchiga, "Dictadura sanitaria” y Uhthoff, "Hacia una política”.

67 Asistencia. Órgano Oficial de la Beneficencia Pública en el Distrito Federal, año I:1 (nov. 1935), pp. 11-18. Asistencia. Órgano Oficial de la Beneficencia Pública en el Distrito Federal, año II:13 (nov. 1936), pp. 29-30. 
“desempeñado líricamente estas difíciles tareas"; en su lugar, prometía la formalización de su empleo y la respectiva incorporación en la burocracia federal de la asistencia. ${ }^{68}$

El 31 de diciembre de 1937 la Secretaría de Gobernación creó la Secretaría de Asistencia Social, la cual se adjudicó la administración de todos los ingresos de la Beneficencia Pública y las funciones asistenciales, entre las cuales destacó el combate a la pobreza y la supresión de la mendicidad, además de la atención de la miseria y la gestión de hospitales, escuelas, comedores, dormitorios y asilos públicos, así como centros de reeducación y readaptación. ${ }^{69}$ Para estas funciones, las trabajadoras sociales fueron incorporadas en la nueva estructura administrativa en el Departamento de Terapia Social.

Con todo y las promesas de una nueva gestión, las trabajadoras sociales siguieron siendo un grupo minoritario de mujeres empleadas por el gobierno: en la Secretaría de la Asistencia Pública médicos, enfermeros y profesores componían mayoritariamente la planta laboral. Las trabajadoras sociales se mantuvieron, por sus salarios, en la escala más baja de sueldos del personal especializado. De acuerdo con el gasto asignado, la nueva Secretaría empleó, en el Departamento de Terapia Social, un "trabajador social A", 10 "investigadores sociales A" y 11 "investigadores sociales B". Para estos 22 empleados, se asignaron salarios entre 180 y 270 pesos, equiparables a los sueldos de los taquígrafos de primera o de los técnicos de laboratorios. ${ }^{70}$ En general, los empleados de esta Secretaría se mantuvieron con sueldos comparativamente bajos; así, en el presupuesto de 1939, la introducción del ramo de Asistencia Pública precisó que el aumento asignado respondía a la necesidad de la federación de incrementar estos servicios en los estados y "regularizar el

${ }^{68}$ El Universal (10 ene. 1936), p. 7.

69 Diario Oficial de la Federación (31 dic. 1937).

70 Secretaría de Hacienda, Presupuesto General, 1938, p. 626. 
pago de sueldos a su personal que antes percibía remuneraciones sumamente bajas". ${ }^{71}$

En la competencia por posicionarse entre los técnicos de la acción social, las trabajadoras sociales siguieron definiendo la especialización de sus funciones, sobre todo frente a los profesionales de la salud. Guillermina Llach, en un artículo publicado hacia la década de 1950, expuso una definición que, a manera de cierre, corrobora algunos aspectos tratados en este artículo, tales como la feminización de esta profesión y la construcción de una disciplina de prácticas y objetivos múltiples para la intervención social:

La enfermera y la trabajadora social. Son dos actividades que, aun cuando ninguna disposición expresamente lo dispone, se han convertido en exclusivas de la mujer, quizá porque quienes a ellas se dedican deben estar en continuo contacto con dolores y miserias, aspectos que parecen ser perfectamente de atención femenina. Ambas profesiones tienen muchos puntos en común, por eso las hemos reunido en un mismo tema: la enfermera, específicamente, atiende los males del cuerpo, miserias de la carne, destrozos de eso que fue barro [...] La trabajadora social atiende las miserias materiales del medio, que muchas veces provienen de males físicos y otras de alteraciones de la mente. Intervienen en los conflictos que crean la ignorancia y la pobreza y partiendo de la organización familiar, coordina los procedimientos para hacer más eficaz el auxilio requerido y menos dura la situación que exige ayuda. ${ }^{72}$

\section{COMENTARIOS FINALES}

Las trabajadoras sociales de la Beneficencia Pública en los años treinta del siglo xx fueron un grupo minoritario de mujeres que inició el recorrido hacia la burocratización del trabajo social

71 Secretaría de Hacienda, Presupuesto General, 1939, p. vi.

72 Llach, "La enfermera", p. 229. 
refinando su instrucción en cursos de especialización y en las primeras escuelas que ofrecieron materias para la formación en el trabajo social.

El ingreso de estas mujeres en la burocracia asistencial estuvo respaldado por la formación escolarizada y el aval del reconocimiento del cargo público en la gestión del Estado. Como consecuencia de la modernización de las responsabilidades sociales del gobierno, esta burocracia conservó rasgos intrínsecos a la Beneficencia decimonónica. En efecto, con tintes "laicos y secularizantes”, concibieron el empleo de las trabajadoras sociales, pero las ubicaron en un nivel de empleo temporal y en la escala inferior de la estructura salarial.

Investidas por la legitimidad que les brindó el compromiso político con el proyecto de reforma social de la revolución mexicana, y la concepción de que el comportamiento altruista y el servicio social eran "naturales” de la condición biológica de la mujer, las trabajadoras sociales afirmaron su posición como empleadas del Estado, además de construir cierta autonomía de sus actividades en servicio público frente a otros actores, por ejemplo, aquellos relacionados con el voluntariado de las organizaciones religiosas o las enfermeras.

La diversidad de funciones vinculadas a un empleo público de carácter temporal supuso una serie de desventajas que limitaron la consolidación de este trabajo dentro de la burocracia. La fragmentación de objetivos, sin embargo, no debe confundirse con una formación inacabada de la profesión, sino como la dispersión que supone la intervención social sobre un mar de necesidades y su tratamiento específico.

En suma, creemos haber mostrado que las trabajadoras sociales no sólo representaron el papel del reformador laico y secular para darle este nuevo rostro al auxilio público, sino que su experiencia se tradujo en una toma de conciencia social que perfiló una manera distinta de entender y tratar la pobreza urbana en el México de los años treinta. 


\section{SIGLAS Y REFERENCIAS}

AHSS, BP, AS, DAES Archivo Histórico de la Secretaría de Salud, Beneficencia Pública, Asistencia Social, Departamento de Acción Educativa y Social, México.

AHSS, BP, AS, AyA Archivo Histórico de la Secretaría de Salud, Beneficencia Pública, Asistencia Social, Alumnos y Asilados, México.

AHSS, BP, D, AS Archivo Histórico de la Secretaría de Salud, Beneficencia Pública, Dirección, Asistencia Social, México.

AHSS, $B P, D G, J D \quad$ Archivo Histórico de la Secretaría de Salud, Beneficencia Pública, Dirección General, Junta Directiva, México.

Abrams, Laura y Laura Curran, "Between Woman: Gender and Social Work in Historical Perspective", en Social Service Review, 78: 3 (sep. 2004), pp. 429-446.

Agostoni, Claudia, "Las mensajeras de la salud. Enfermeras visitadoras en la ciudad de México durante la década de los 1920", en Estudios de Historia Moderna y Contemporánea de México, 33 (ene.-jun. 2007), pp. 89-120.

Aréchiga Córdoba, Ernesto, “Dictadura sanitaria, educación y propaganda higiénicas en el México revolucionario, 1917-1934”, en Dynamo, 25 (1991), pp. 117-143.

Arrom, Silvia Marina, Volunteering for a Cause: Gender, Faith, and Charity in Mexico from the Reform to the Revolution, Albuquerque, Universidad de Nuevo México, 2016.

Barbosa, Mario, "Empleados públicos en la ciudad de México: condiciones laborales y construcción de la administración pública (1903-1931)”, en REMEDI y BARbosa (comps.), 2014, pp. 137-158.

Bastian, Jean Pierre, “Modelos de mujer protestante: ideología religiosa y educación femenina, 1880-1910”, en Ramos Escandón (coord.), 2006, pp. 163-180.

Bazant, Mílada, “Análisis comparativo de la educación en México”, en GaLván LAFArga y López Pérez (coords.), 2008, pp. 237-251.

Beteta, Ramón, La mendicidad en México, México, Beneficencia Pública, A. Mijares y Hno., 1931. 
Biernat, Carolina, Juan Manuel Cerdá y Karina Inés RamacciotTi (dirs.), La salud pública y la enfermería en la Argentina, Bernal, Argentinas Universidad Nacional de Quilmes, 2015.

Biernat, Carolina y Karina Ramacciotti (ed.), Historia de la salud y enfermedad. Bajo la lupa de las ciencias sociales, Buenos Aires, Biblos, 2014.

Bohoslavsky, Ernesto y Germán Soprano, "Una evaluación y propuestas para el estudio del Estado en la Argentina", en BohosLavsky y Soprano (eds.), 2010, pp. 9-55.

Bohoslavsky, Ernesto y Germán Soprano (eds.), Un Estado con rostro humano. Funcionarios e instituciones estatales en Argentina (desde 1880 a la actualidad), Buenos Aires, Prometeo, Universidad Nacional de General Sarmiento, 2010.

Calderón Mólgora, Marco Antonio, "Educación rural, trabajo social y Estado en México: 1920-1933", en Revista Mexicana de Historia de la Educación, en http://www.somehide.org/images/documentos/articulosRevista8/ RMHE8_2_20_12_16.pdf (2016), consultado el 2 de agosto de 2017, pp. 153-173.

Cano, Gabriela, "Género y construcción cultural de las profesiones en el Porfiriato: magisterio, medicina, jurisprudencia y odontología”, en Historia y Grafía (14) (2000), pp. 207-243.

CANo, Gabriela, "Las feministas en campaña: la primera mitad del siglo XIX”, en Debate Feminista, 2 (4) (1991), pp. 269-292.

Cano, Gabriela, Se llamaba Elena Arizmendi, México, Tusquets Editores, 2010.

Castro, Pedro, A la sombra de un caudillo. Vida y muerte del general Francisco R. Serrano, México, Plaza y Janés, 2005.

Castro Carbajal, Beatriz, La relación entre la Iglesia católica y el Estado colombiano en la asistencia social, c. 1870-1960, Cali, Programa Editorial Universidad del Valle, 2014.

Castro Sánchez, Ana Elisa, "Ser trabajadora social en México: el impacto de las ideologías de género en el surgimiento de las escuelas de Trabajo Social", en el Repositorio Académico Digital de la Universidad Autónoma de Nuevo 
León. http://eprints.uanl.mx/8719/1/art4/20/289/29.pdf, consultado el 2 de agosto de 2017.

Cerdá, Juan Manuel, Gloria Guadarrama, María Dolores Lorenzo y Beatriz MoreYra (coords.), El auxilio en las ciudades. Instituciones, actores y modelos de protección social, Argentina y México. Siglos XIX y XX, México, El Colegio Mexiquense, Centro de Estudios Históricos Prof. Carlos S. A. Segreti, 2015.

Crespo Reyes, Sofía, "Entre la filantropía y la práctica política. La Unión de Damas Católicas Mexicanas en la ciudad de México (1860-1930)", tesis de doctorado en historia, México, Instituto Dr. José Ma. Luis Mora, 2016.

Evangelista, Eli, Historia del trabajo social en México, México, Plaza y Valdés, Escuela Nacional del Trabajo Social, Universidad Nacional Autónoma de México, 1998.

Fernández García, Tomás y Rafael de Lorenzo García (eds.), Trabajo social. Una historia global, Bogotá, Mc Graw-Hill, Interamericana de España, 2015.

Galván Lafarga, Luz Elena y Oresta López Pérez (coords.), Entre imaginarios y utopías: historias de maestras, México, Universidad Nacional Autónoma de México, Programa Universitario de Estudios de Género, Centro de Investigaciones y Estudios Superiores en Antropología Social, El Colegio de San Luis, 2008.

Guadarrama, Gloria y Paolo Riguzzi, "La trayectoria legislativa de la beneficencia privada en México, del porfiriato hasta mediados de siglo xx: cambio institucional y gobernanza", en CERDÁ, GuAdARRAMA, LoRENZO y Moreyra (coords.), 2015, pp. 25-52.

Guadarrama Sánchez, Gloria "Presencia de la mujer en la asistencia social en México”, en Economía, Sociedad y Territorio, II: 5 (ene.-jun. 1999), pp. 117-147.

Hugo, Víctor, Los miserables, "El interior de la desesperación”, cap. V. e-artnow, 2013.

Illanes, María Angélica, Cuerpo y sangre de la política. La construcción bistórica de las Visitadoras Sociales (1887-1940), Santiago de Chile, Lom. Ediciones 2007. 
Katz, Michael B., In the Shadow of the Poorhouse. A Social History of Welfare in America, Nueva York, Basic Books, 1986.

Lemaitre, Monique J., Elvia Carrillo Puerto. La monja roja del Mayab, México, Ediciones Castillo, 1998.

LLACH, Guillermina, "La enfermera y la trabajadora social”, en Semanario Gil-Blas, Monterrey, Nuevo León, 1950, pp. 223-234.

Lorenzo Río, María Dolores, "La acción asistencial ante la pobreza en la Ciudad de México. Historia de una práctica discontinua, 1930-1934”, en Tzintzun [en prensa].

LOREnzo Río, María Dolores, "El análisis de la pobreza y la campaña contra la mendicidad en la Ciudad de México, 1929-1931", en Historia Mexicana, LXVII: 4 (268) (abril-junio 2018), pp. 1677-1724.

LoREnzo Río, María Dolores, "Ley y eficacia. La centralización administrativa de la beneficencia en la Ciudad de México, 1876-1904", en Signos Históricos, XIX: 37 (ene.-jun. 2017), pp. 64-95.

Migdal, Joel S., Estados débiles, Estados fuertes, México, Fondo de Cultura Económica, 2011.

Mitchell, Stephanie y Patience A. Schell (eds.), The Women's Revolution in Mexico, 1910-1953, Maryland, Lanham, 2007.

Oıikión Solano, Verónica, “Cuca García: trazando el surco socialista a través de la educación”, en Signos Históricos, xviI: 34 (jul.-dic. 2015), pp. $42-77$.

Olcott, Jocelyn H., Revolutionary Women in Postrevolutionary Mexico, Durham, NC., Duke University Press, 2005.

Ornelas Bernal, Adriana, Nelia Tello Peón y José Manuel León Cristerna, "Historia del trabajo social en México", en Fernández García y LORENZo García (eds.), 2015, pp. 245-266.

Plotkin, Mariano y Eduardo Zimmermann (comps.), Las prácticas del Estado. Política, sociedad y elites estatales en la Argentina del siglo XX, Buenos Aires, Edhasa, 2012.

Porter, Susie, "Empleadas públicas: normas de feminidad, espacios burocráticos e identidad de la clase media en México durante la década de 1930", en Signos Históricos, 11 (ene.-jul. 2004), pp. 41-63. 
Publicaciones de la Secretaría de Educación Pública, "Folleto de la Escuela Nacional de Enseñanza Doméstica”, México, Publicaciones de la Secretaría de Educación Pública, 1925.

Ramos escandón, Carmen (coord.), Presencia y transparencia: la mujer en la historia de México, México, El Colegio de México, 2006.

Remedi, Fernando J. y Mario Barbosa (comps.), Cuestión social, políticas sociales y construcción del Estado Social en América Latina, siglo XX, México, Centro de Estudios Históricos Prof. Carlos S. A. Segreti, Universidad Autónoma Metropolitana-Cuajimalpa, 2014.

Sanders, Nichole, Gender and Welfare in Mexico. The Consolidation of a Posrevolutionary State, Pennsylvania, State University Press, 2011.

SAuri Riancho, Dulce María, "Violencia política y resilencia. El caso de Elvia Carrillo Puerto", en P. Galeana et al., Mujeres y constitución: de Hermila Galindo a Griselda Álvarez, México, Biblioteca Constitucional, Instituto Nacional de Estudios Históricos de las Revoluciones de México, Secretaría de Cultura, Gobierno del Estado de México, 2017.

Secretaría de Hacienda y Crédito Público, Presupuesto General de Egresos de la Federación 1938, México, Secretaría de Hacienda y Crédito Público, 1939.

Secretaría de Hacienda y Crédito Público, Presupuesto General de Egresos de la Federación 1939, México, Secretaría de Hacienda y Crédito Público, 1940.

Tuñón Pablos, Esperanza, Mujeres que se organizan. El Frente Único Pro Derechos de la Mujer 1935-1938, México, Universidad Nacional Autónoma de México, Miguel Ángel Porrúa, 1992.

Uhthoff López, Luz María, "Hacia una política asistencial. La creación de la Secretaría de Asistencia Pública en México, 1937-1940", en Remedi y BARBOSA (comps.), 2014, pp. I 59-174.

Valero Chávez, Aída, El trabajo social en México, desarrollo y perspectivas, México, Universidad Nacional Autónoma de México, 1994. 